\title{
Abrasion resistance of high early-strength concrete for rapid repair
}

\author{
Nader Ghafoori ${ }^{1}$, Matthew O. Maler ${ }^{1}$, Meysam Najimi ${ }^{2}$, Ariful Hasnat ${ }^{1}$ \\ ${ }^{1}$ Department of Civil and Environmental Engineering and Construction, University of Nevada, Las Vegas 4505 S Maryland \\ Pkwy Street, Las Vegas, USA \\ ${ }^{2}$ Department of Civil, Construction, and Environmental Engineering, Iowa State University, Ames, IA 50011, USA
}

\begin{abstract}
This paper examines the abrasion resistance of high early-strength concrete developed for rapid repair of highways and bridge decks. The cement types chosen for this study included ASTM Type III, ASTM Type V, and Calcium Sulfoaluminate (CSA) cements. A cement content of $386 \mathrm{~kg} / \mathrm{m}^{3}\left(650 \mathrm{lb} / \mathrm{yd}^{3}\right)$ was maintained for all studied concretes. Test samples were tested after 24 hours and 28 days of curing in order to evaluate compressive strength and depth of wear. Test results revealed that the opening time to attain minimum required compressive strength for CSA cement concrete was one hour, whereas the values for Type V and Type III cement concretes were 8.5 and 6 hours, respectively. After 24 hours curing, CSA cement concrete displayed the highest strength, but lowest resistance to wear. The 28-day cured CSA cement concrete produced the highest strength and resistance to abrasion, while Type III cement concrete showed a similar strength, but lower resistance to wear, when compared to those of the Type V cement concrete.
\end{abstract}

\section{Introduction}

With more than $60 \%$ of the US interstate highway system paved with concrete, surface wear due to traffic loading or environmental conditions is one of the main reasons that can reduce the quality of ride. As a result, major maintenance and repair works are required to maintain these huge chains of road network [4]. In recent years, significant advancement has been made in the development of fast repair techniques of reinforced concrete pavements. High Early-Age Strength (HES) concrete was traditionally regarded as a concrete that achieves a loading strength in a matter of days rather than weeks. However, in the last 10-15 years, this time has been reduced down to a matter of hours [1]. The required minimum compressive strength is determined on a case-by-case basis depending on a given project. In construction applications for structures and dwellings the minimum allowed by the International Building Code is 17.24 MPa (2500 psi) (IBC 2012), while in road and bridge construction the minimum requirement is typically $20.68 \mathrm{MPa}$ (3000 psi) [2].

Concrete mechanical properties play an important role in the abrasion of concrete [5-8]. Siddique and Khatib [9] found that an increase in compressive strength and modulus of elasticity of concrete improves the overall abrasion resistance. Experimental work on the abrasion resistance of highway concrete pavements subjected to heavy traffic from studded tires has been carried out. Increasing the concrete strength from 50 to $100 \mathrm{MPa}$ (7100 to $14,300 \mathrm{psi}$ ) reduced the depth of wear of concrete by roughly $50 \%$ [9].
In recent years, Calcium Sulfoaluminate Cement (CSA) has become widely used in concrete repair works due to its outstanding properties of volume stability and rapid strength gain [10]. In comparison to Type V cement, Type III and CSA cement are expensive. In addition, some of their long-term properties may be compromised in exchange for rapid strength development. Therefore, they tend to be used as emergency repairs and in high priority situations such as inner-city freeway exchanges and airport runways, or situations in which a significant cost is associated with the elapsed closure time. In this context, an experimental program was undertaken to compare the effect of different cement types on abrasion resistance and compressive strength development at different curing ages for rapid repair of concrete pavements and highways.

\section{Experimental Procedures}

\subsection{Materials}

Locally available fine and coarse aggregates were used. Their size distribution complied with the requirements of ASTM C136 and ASTM C33 for coarse and fine aggregates. ASTM Type III, Type V, and Calcium Sulfoaluminate (CSA) cements were used to produce standard high early-strength concretes. Table 1 provides the composition and Blaine Fineness of the cements used in this study. The CSA cement had the highest fineness when compared with that of the Type III and Type V cements. Polycarboxylate high-range-water-reducer (HRWR), Accelerating admixture, and air-entrainer

* Corresponding author: hasnat@unlv.nevada.edu 
(AE) were also used to maintain the desired fresh and early-strength properties of concrete.

\subsection{Mixture constituents and proportions}

Three mixture proportions were selected to evaluate the compressive and wear properties of concrete. The mixture constituents and proportions are given in Table 2. The total cement content was kept constant at 386 $\mathrm{kg} / \mathrm{m}^{3}$. As listed in Table 2, three different water-tocementitious ratios, $0.35,0.275$, and 0.40 were used for Type III, Type V, and CSA cement mixtures, respectively. The basis for selection of different w/c was to achieve the earliest opening time (the highest earlyage strength development) while providing adequate fresh properties. The workability of the studied concretes was kept constant at $125 \pm 25 \mathrm{~mm}(5 \pm 1$ in). To accelerate the hardening process, a higher amount of accelerating admixture was used for Type III and Type V cement concretes. A small amount of accelerating admixture was also used in the CSA cement concrete mixture. All studied concretes contained air-entraining admixtures (AE) to achieve a uniform air content of $4 \pm 1 \%$.

Table 1. Cement composition and Blaine fineness.

\begin{tabular}{|c|c|c|c|}
\hline Potential Compounds & $\begin{array}{l}\text { ASTM Type } \\
\text { III }\end{array}$ & ASTM Type V & $\begin{array}{l}\text { CSA } \quad \text { (Rapid } \\
\text { set) }\end{array}$ \\
\hline $\mathrm{C}_{3} \mathrm{~S}(\%)$ & 50 & 58 & \multirow{4}{*}{$\begin{array}{l}\text { Proprietary } \\
\text { information }\end{array}$} \\
\hline $\mathrm{C}_{2} \mathrm{~S}(\%)$ & 24 & 16 & \\
\hline $\mathrm{C}_{3} \mathrm{~A}(\%)$ & 11 & 4 & \\
\hline $\mathrm{C}_{4} \mathrm{AF}(\%)$ & 4 & 12 & \\
\hline $\begin{array}{l}\text { Blaine Fineness } \\
\left(\mathrm{m}^{2} / \mathrm{kg}\right)\end{array}$ & 496 & 420 & $>500$ \\
\hline
\end{tabular}

Table 2. Mixture proportions

\begin{tabular}{|c|c|c|c|c|c|c|c|}
\hline Mixture id & $\mathrm{w} / \mathrm{cm}$ & $\begin{array}{c}\mathrm{C}^{*} \\
\left(\mathrm{~kg} / \mathrm{m}^{3}\right)\end{array}$ & $\begin{array}{c}\mathrm{FA}^{*} \\
\left(\mathrm{~kg} / \mathrm{m}^{3}\right)\end{array}$ & $\begin{array}{c}\mathrm{CA}^{*} \\
\left(\mathrm{~kg} / \mathrm{m}^{3}\right)\end{array}$ & $\begin{array}{l}\text { WRA* } \\
\left(\mathrm{kg} / \mathrm{m}^{3}\right)\end{array}$ & $\begin{array}{c}\mathrm{Acc}^{*} \\
\left(\mathrm{~kg} / \mathrm{m}^{3}\right)\end{array}$ & $\begin{array}{c}\text { Air } \\
\text { entrainer } \\
\left(\mathrm{kg} / \mathrm{m}^{3}\right)\end{array}$ \\
\hline Type III-AE & 0.35 & 386 & 898 & 1097 & 1.65 & 7.71 & 1.9 \\
\hline Type V-AE & 0.275 & 386 & 933 & 1141 & 3.24 & 7.71 & 2.1 \\
\hline CSA-AE & 0.40 & 386 & 865 & 1057 & 2.20 & 1.21 & 0.11 \\
\hline
\end{tabular}

\subsection{Mixing, sampling, curing, and testing}

A pan-style counter-current mixer, having a constant speed of 60 RPM, was used. After pouring freshly-mixed concrete into the mold, specimens were densified for a period of approximately 7 seconds using a vibrating table. Both one day and 28 days moist curing were utilized to cure concrete specimens. To evaluate compressive strengths, cylindrical specimens with dimensions of $102 \mathrm{~mm} \times 203 \mathrm{~mm}$ (4 in. $\times 8$ in.) were used and tested in accordance with ASTM C39. Resistance to wear of the studied high early-age strength concretes were evaluated in accordance with the ASTM C779, Procedure A, Ball Bearings. This test method was selected as it best simulates rolling traffic and the severe wearing found in industrial and commercial applications, as well as highway pavements exposed to traffic wear from vehicles having tires equipped with snow chains or studs. Two $152 \mathrm{~mm}$ x $152 \mathrm{~mm}$ x $152 \mathrm{~mm}$ (6 in. x 6 in. $\mathrm{x}$
6 in.) cube-shaped samples for each curing type were used to obtain the wear depth. The testing machine used for this study is shown in Figure 1.

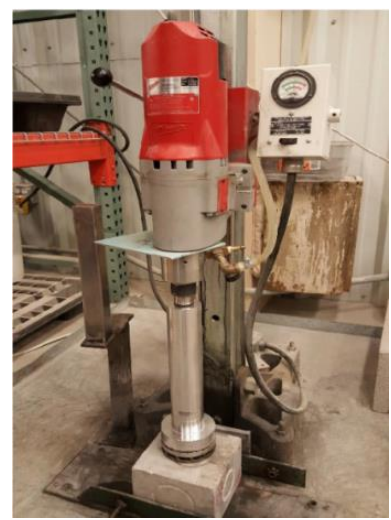

Fig. 1. Abrasion resistance testing machine. 


\section{Results and Discussion}

\subsection{Setting time}

When Type V Portland cement was used, the initial setting time of HES concretes was at approximately 85 minutes, whereas the final setting time was 169 minutes. For Type III cement, the initial setting time was recorded at 70 minutes and the final setting time was 129 minutes. The reduction in the setting times in Type III, as compared to those of Type V Portland cement, is due to Type III cement having an increased $\mathrm{C}_{3} \mathrm{~S}$ content and higher Blain Fineness. It is well established that an increase in water-to-cement ratio leads to an increase in setting times. Since the studied concretes made with Type III Portland cement had a higher water-to-cement ratio, it would suggest that its $\mathrm{C}_{3} \mathrm{~S}$ and Blain Fineness had greater influence on setting time than water-tocement ratio. High early strength concretes containing CSA cement were not evaluated for setting times since its manufacturer assigned 20 minutes for initial setting and 30 minutes for final setting.

\subsection{Opening time}

The time to achieve the required $21 \mathrm{MPa}$ (3000 psi) compressive strength (The opening time) using Type III, Type V, and CSA cement concrete is given in Figure 2. It is observed that the opening time for Type III cement concrete was lower as compared to that of Type V cement concrete. This is due to the higher fineness and presence of a high amount of $\mathrm{C}_{3} \mathrm{~S}$ in Type III cement. Also, air-entrainer acted as a retarder to the concrete and increased the opening time for both Type III and type V cement concretes. As per manufacturer recommendation, the CSA cement concrete mixture was made with addition of retarder with al hour opening time. All three mixtures exceeded the minimum opening time compressive strength requirement of $21 \mathrm{MPa}$.

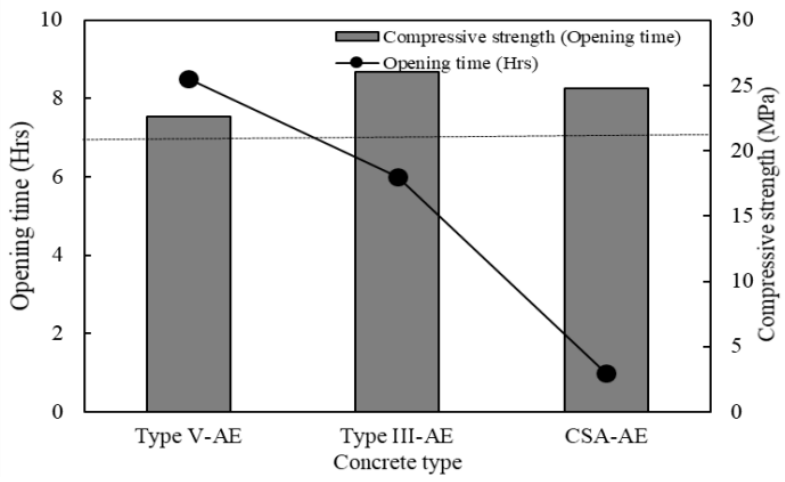

Fig. 2. Opening time and compressive strength of concretes made with Type III, Type V, and CSA cement.

\subsection{Compressive strength}

The influence of curing age and cement type on the compressive strength are shown in Figure 3. When Type $\mathrm{V}$ cement was used, the 28 day compressive strength of the concrete increased by $41 \%$, as compared to the 24 hour compressive strength of the same mixture. For Type III cement concrete, the 28 day compressive strength of the concrete increased by $31 \%$, as compared to the 24-hour compressive strength of the same mixture. For CSA cement mixtures, the 28-day compressive strength of the concrete increased by $20 \%$, as compared to the 24-hour compressive strength of the same mixture. Concrete with Type V cement showed a higher compressive strength development at 28 days as compared to the 24 hours compressive strength. This is mainly due to presence of lower $\mathrm{C}_{3} \mathrm{~S}$ in Type $\mathrm{V}$ cement concrete as opposed to that of the Type III and CSA cement concrete mixtures. On the whole, in both 24 hours and 28 days tests, CSA cement showed the highest compressive strength amongst the three studied mixtures.

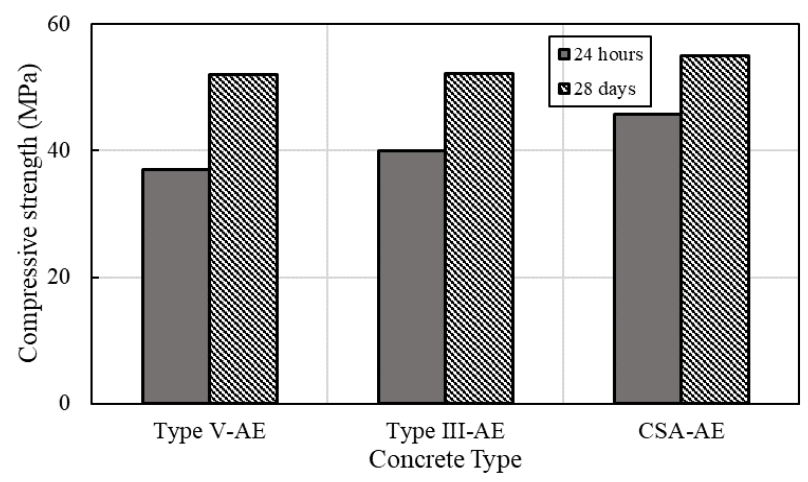

Fig. 3. Effect of curing age on compressive strength of concretes made with Type III, Type V, and CSA cement.

\subsection{Abrasion resistance}

The depth of wear of the concretes at different test ages is presented in Figure 4. The use of Type V cement in the mixture resulted in a $23 \%$ lower abrasion depth at 28 days than that at 24 hours. On the other hand, concrete containing Type III cement produced a $16 \%$ lower abrasion depth at 28 days than that of the 24-hour cured specimen. A significant improvement was observed in abrasion resistance for the CSA cement concrete mixture with $44 \%$ lower abrasion depth at 28 days testing in comparison with 24 hours testing. Figure 5 represents the abrasion depth and compressive strength of the studied concretes at 28 days curing age. Increases in the compressive strength reduced the depth of wear significantly. As can be seen, the compressive strength of the CSA cement concrete mixture also had the highest compressive strength and the lowest depth of abrasion amongst all three studied concrete mixtures. Table 3 shows the percentage increase in compressive strength and reduction in abrasion depth of the studied concretes when the curing age increased from 24 hours to 28 days. 


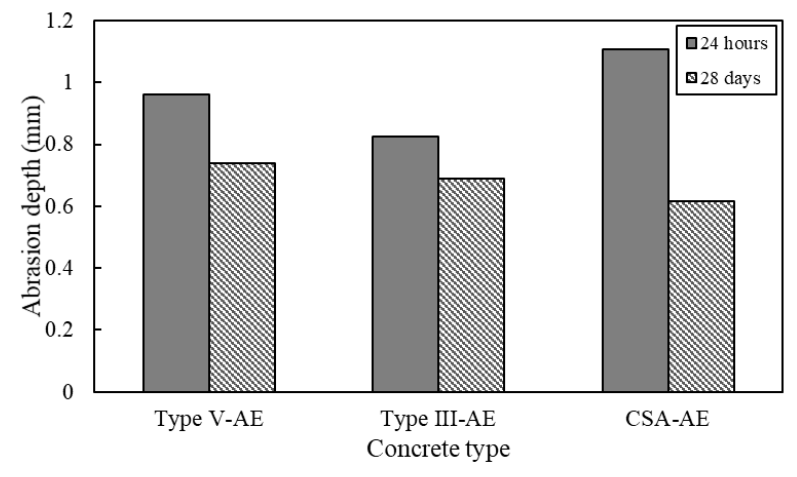

Fig. 4. Effect of curing age on abrasion depth for Type III, Type V, and CSA cement.

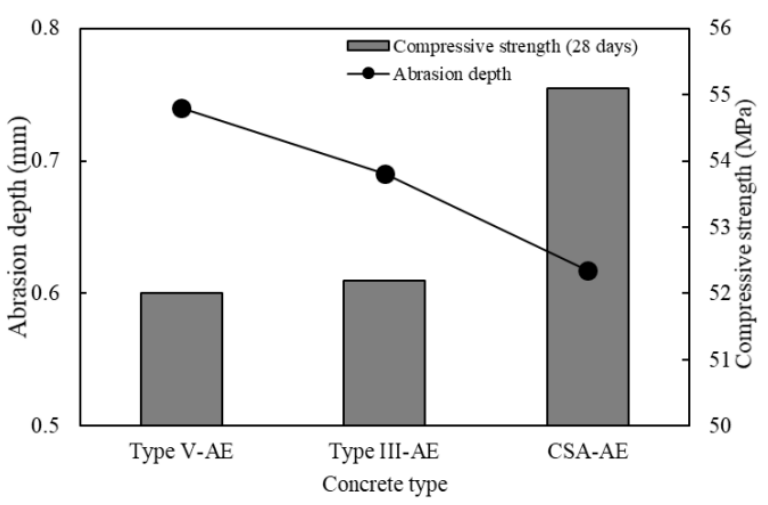

Fig. 5. Effect of curing age on failure time of Type III and Type $\mathrm{V}$ cement concrete.

Table 3. Influence of curing age on strength and resistance to abrasion

\begin{tabular}{|c|c|c|}
\hline Mixture Type & $\begin{array}{c}\text { \% increase in } \\
\text { Compressive } \\
\text { strength }\end{array}$ & $\begin{array}{c}\text { \% decrease in depth } \\
\text { of wear }\end{array}$ \\
\hline Type V-AE & 41 & 23 \\
\hline Type III-AE & 31 & 16 \\
\hline CSA-AE & 20 & 44 \\
\hline
\end{tabular}

\section{Conclusions}

Based on the results of the investigation, the main conclusions are as follows:

- All studied concretes attained the minimum opening time compressive strength of $21 \mathrm{MPa}$ within a short period of time. The resulting opening times were 8.5, 6, and 1 hours for Type V, Type III, and CSA cement concretes, respectively. CSA cement concrete showed the highest 24-hour and 28-day cured compressive strengths amongst the three studied concretes. However, 28 days curing reduced the strength gap amongst the three studied mixtures.

- $\quad$ At 24 hours curing, CSA cement concrete showed the highest depth of abrasion in comparison with that of the Type III and Type V cement concretes.

- $\quad$ Once curing age was extended to 28 days, CSA cement concrete displayed the lowest depth of wear and the highest compressive strength.

\section{Acknowledgements}

This study was made possible by the financial contributions of The US Federal Highway Administration through UTC Solaris Consortium. Thanks are also extended to a number of producers and manufacturers for providing materials used in this investigation.

\section{References}

1. T.R. Naik \& B.W. Ramme: High early strength concrete containing large quantities of fly ash. In: ACI Materials Journal, 86 (1989) 2, PP. 111-116.

2. M.O. Maler: High Early-Age Strength Concrete for Rapid Repair. In: MSc Diss. University of Nevada, Las Vegas (2017).

3. P. Suraneni, J. Monical, E. Unal, Y. Farnam, \& J. Weiss: Calcium oxychloride formation potential in cementitious pastes exposed to blends of deicing salt. In: ACI Materials Journal 114 (2017) 4, PP. 631-641.

4. K. Amini, S. Sadati, H. Ceylan, \& P.C. Taylor: Effects of mixture proportioning, curing, and finishing on concrete surface hardness. In: ACI Materials Journal 116 (2019) 2, PP. 119-126.

5. T.R. Naik, S.S. Singh, \& M.M. Hossain: Abrasion resistance of concrete as influenced by inclusion of fly ash. In: Cement and Concrete Research 24 (1194) 2, PP. 303-312.

6. A. Nanni: Abrasion resistance of roller compacted concrete. In: ACI Materials Journal 86 (1989) 6, PP. 559-565.

7. N. Ghafoori \& H. Diawara: Abrasion resistance of fine aggregate-replaced silica fume concrete. In: ACI Materials Journal 96 (1999) 5, PP. 559-569.

8. N. Ghafoori \& B.M. Sukandar: Abrasion resistance of concrete block pavers. In: ACI Materials Journal 92 (1995) 1, PP. 25-36.

9. O.E. Gjørv, T. Baerland, \& H.R. Ronning: Abrasion resistance of high-strength concrete pavements. In: Concrete International 12 (1990) 1, PP. 45-48.

10. J.S. Yeung, M.C. Yam, \& Y.L. Wong: 1-Year development trend of concrete compressive strength using Calcium Sulfoaluminate cement blended with $O P C, \quad P F A$ and GGBS. In: Construction and Building Materials 198 (2019), PP. 527-536. 